\title{
Formulation development and evaluation of zolmitriptan oral soluble films using $2^{2}$ factorial designs
}

\author{
Poluri Koteswari, G. Puja Sravanthi ${ }^{1}$, M. Mounika ${ }^{1}$, S. K. Mohammed Rafi ${ }^{1}$, K. Nirosha ${ }^{1}$ \\ Departments of Pharmaceutics, Hindu College of Pharmacy and ${ }^{1}$ Vignan Pharmacy College, Guntur, Andhra Pradesh, India
}

\begin{abstract}
Objective: The present investigation involves the development of zolmitriptan oral soluble film (OSF) formulations and optimization with quality by design (QBD) using natural polymers and evaluation. Materials and Methods: Initially, various natural polymers such as sodium alginate, pectin, and gelatin were screened by casting films using solvent casting technique and the prepared films were evaluated. Based on the physical and mechanical properties, sodium alginate was selected as best film former and zolmitriptan-loaded films were casted. The formulation was optimized with the help of $2^{2}$ factorial experimental designs (QBD) in which sodium alginate concentration and plasticizer concentrations were used as factors and at two levels. The drug-loaded films were evaluated for various mechanical, physicochemical properties, and in vitro drug release properties. Factor effects were interpreted by calculating the main factor effects and by plotting the interaction plots. Results: Thickness of the films, disintegration time, and percent drug loading efficiency were in the range of $0.698 \pm 0.13-1.318 \pm 0.22 \mathrm{~mm}, 175 \pm 3.1-280 \pm 1.7 \mathrm{~s}$, and $68.34 \pm 0.5-94.70 \pm 0.7 \% \mathrm{w} / \mathrm{v}$, respectively. Cumulative percent drug released was $61.8 \pm 2.6-94.7 \pm 4.1 \%$ after 30 min. Polymer concentration at two levels of plasticizer had statistically significant effect on drug loading efficiency and in vitro drug release rate. $X_{2}$ formulation was found to be excellent in drug loading efficiency and in vitro drug release profiles; hence, drug excipient compatibility studies using Fourier transform infrared spectroscopy and stability studies for 60 days were carried out for $X_{2}$ formulation and found to be stable. Conclusion: Sodium alginate OSFs containing zolmitriptan was successfully prepared, optimized, and evaluated.
\end{abstract}

Key words: Interaction plots, oral soluble film, quality by design, sodium alginate, zolmitriptan

\section{INTRODUCTION}

Migraine is a type of neurological syndrome affecting at least $12-28 \%$ of the world's population at any one time. ${ }^{[1]}$ This disorder is characterized by splitting headaches that comes in waves and is very debilitating becoming a major handicap for the sufferer. Clinical scientists and medical doctors have known about the functional impairment of the brain in patients during a migraine attack. One recent study has also confirmed that the cognitive abilities of patients who suffer repeated migraine attacks decreases over a span of time. ${ }^{[2,3]}$ Several drugs and

\section{Address for correspondence:}

Dr. Poluri Koteswari,

Hindu College of Pharmacy, Guntur, Andhra Pradesh, India.

E-mail: polurikoteswari@gmail.com

\begin{tabular}{|l|l|}
\hline \multicolumn{2}{|c|}{ Access this article online } \\
\hline Quick Response Code: & Website: \\
\hline
\end{tabular}

dosage forms are available in the market, and each has its own advantages and disadvantages. Zolmitriptan is a selective 5-hydroxy tryptamine (5HT1B/1D) receptor agonist and works by narrowing blood vessels in the brain, which helps to relieve migraines. It is chemically designated as (S)-4-([3-[2-(dimethyl amino) ethyl]-1H-indol-5yl] methyl)-2 oxazolidinone. ${ }^{[4]}$ Its oral bioavailability is $40 \%$ and elimination half-life is between $3 \mathrm{~h}$ and $1.5 \mathrm{~h}$. Zolmitriptan is available in the market as fast disintegrating tablets ${ }^{[4]}$ and nasal sprays. ${ }^{[5,6]}$ In conventional tablet dosageforms, a sequence of events such as disintegration and dissolution of the tablet are involved before the drug absorbs into systemic circulation and elicits its therapeutic

\footnotetext{
This is an open access article distributed under the terms of the Creative Commons Attribution-NonCommercial-ShareAlike 3.0 License, which allows others to remix, tweak, and build upon the work non-commercially, as long as the author is credited and the new creations are licensed under the identical terms.
}

For reprints contact: reprints@medknow.com

How to cite this article: Koteswari P, Sravanthi GP, Mounika M, Mohammed Rafi SK, Nirosha K. Formulation development and evaluation of zolmitriptan oral soluble films using $2^{2}$ factorial designs. Int J Pharma Investig 2016;6:201-6. 
action. In liquid formulation, it shows action immediately, but it has very short half-life. Generally, drugs are unstable in liquid preparations. ${ }^{[7]}$ To overcome the above drawbacks, oral soluble films (OSFs) came into existence. OSF drug delivery has emerged as an advanced alternative to the traditional tablets, capsules, and liquids. They are similar in size, shape, and thickness to a postage stamp. OSF not only ensures more accurate administration of drugs but also can improve the ease of administration. ${ }^{[8,9]}$ These properties are, especially beneficial for pediatric, geriatric, and neurodegenerative disease patients where proper and complete dosing can be difficult. Therefore, the focus of the present study was to develop an optimum formulation with the help of factorial designs of OSF containing zolmitriptan using natural polymers.

\section{MATERIALS AND METHODS}

\section{Materials}

Zolmitriptan (was a gratis sample from Dr. Reddys Laboratories, India), sodium alginate, pectin, gelatin, mannitol and aspartame (were purchased from qualingens fine chemicals, India), ascorbic acid and propylene glycol (were purchased from loba chemie, India), and all other materials were of analytical grade and purchased from NSB pharmaceuticals, Vijayawada, India.

\section{Methods}

\section{Solubility studies of zolmitriptan}

Solubility studies of zolmitriptan were carried in different phosphate buffer solutions. Phosphate buffers of $\mathrm{pH}$ 6.4, 6.8, and 7.4 were prepared as per the Indian Pharmacopoeal specifications and $5 \mathrm{ml}$ of each buffer solution was taken in three different conical flasks, an excess amount of drug was added and kept on the orbital shaker at $100 \mathrm{rpm}$ for 2 h. Later, the conical flasks were kept aside over night to equilibrate the dissolved and undissolved portions of drug. After $24 \mathrm{~h}$, the samples were filtered, and absorbance was measured at $224.2 \mathrm{~nm}$ using ultraviolet (UV)-visible spectrophotometer (ELICO SL 159) after making necessary dilutions. Using standard calibration curve, concentration of dissolved drug was calculated.

\section{Screening of film forming polymers}

Films were prepared using natural polymers such as pectin, gelatin, and sodium alginate by solvent casting technique. The polymer was dissolved in water to form a viscous solution. All other ingredients, viz., plasticizer (propylene glycol) and a combination of mannitol and aspartame as sweeteners except the drug were added. Then, the solution was sonicated for $15 \mathrm{~min}$ to remove entrapped air. Finally, the films were casted on a plain glass plate in a measured area and allowed to dry for $1 \mathrm{~h}$ in a hot air oven at $60^{\circ} \mathrm{C}$. Different film forming agents were casted into films and examined for their physical and mechanical properties such as appearance, thickness, folding endurance, and time to dissolve the film.
Preparation optimization of drug-loaded films using quality by design ( $2^{2}$ factorial design)

Sodium alginate was selected as the best film former based on the physical and mechanical properties of the casted placebo films for the preparation of zolmitriptan OSF. Sodium alginate was allowed to soak in required quantity of water for sufficient time, i.e., $10 \mathrm{~min}$ until it formed a uniform viscous solution. Drug was dissolved in $10 \mathrm{ml}$ of water and it was added to the polymeric solution. Then, all other ingredients were added and the entire mixture was sonicated to remove the entrapped air. This solution was casted as film on a glass plate in a measured area and allowed to dry for $1 \mathrm{~h}$ in a hot air oven at $60^{\circ} \mathrm{C} \cdot{ }^{[10]}$ The formulation was optimized by quality by design, i.e., $2^{2}$ factorial experiments. The experiment in which two or more factors are investigated simultaneously is called a factorial design. The different designated categories of the factors are called levels. In factorial designs, we may study not only the effects of individual factors but also if the experiment is properly conducted the interaction between the factors. ${ }^{[1]}$ The factors, levels of factors, and compositions of various drug loaded films are given in Tables 1-3.

\section{Characterization of oral soluble films Thickness}

The thickness of the film was measured at five locations (center and four corners) using Vernier calipers, and it was averaged to determine the mean thickness in $\mathrm{mm}$. Samples with air bubbles, nicks, and mean thickness variation of $>5 \%$ were excluded from analysis.

\section{Folding endurance}

To determine the folding endurance, a strip of film was cut and repeatedly folded at the same place till it broke. The

\section{Table 1: Factorial designs}

\begin{tabular}{lcc}
\hline No. of trials & Factor-A & Factor-B \\
\hline$X_{1}(1)$ & -1 & -1 \\
$X_{2}(b)$ & -1 & +1 \\
$X_{3}(a)$ & +1 & -1 \\
$X_{4}(a b)$ & +1 & +1 \\
\hline
\end{tabular}

Factors: 1) Polymer concentration - Factor-A, 2) Plasticizer concentration - Factor-B

Table 2: Code for levels of 22 factorial designs

\begin{tabular}{lccc} 
Levels & Code & Polymer quantity & Plasticizer quantity \\
\hline High level & +1 & $1.25 \mathrm{GM}$ & $1 \mathrm{ml}$ \\
Low level & -1 & $0.75 \mathrm{GM}$ & $0.5 \mathrm{ml}$ \\
\hline
\end{tabular}

Table 3: Compositions of various drug loaded oral soluble films

\begin{tabular}{lcccc} 
Name of ingredient & $\mathbf{X}_{\mathbf{1}}(\mathbf{1})$ & $\mathbf{X}_{\mathbf{2}}(\mathbf{a})$ & $\mathbf{X}_{\mathbf{3}}(\mathbf{b})$ & $\mathbf{X}_{\mathbf{4}}(\mathbf{a b})$ \\
\hline Drug $(\mathrm{mg})$ & 50 & 50 & 50 & 50 \\
Sodium alginate $(\mathrm{gm})$ & 0.75 & 0.75 & 1.25 & 1.25 \\
Propylene glycol $(\mathrm{ml})$ & 0.5 & 1 & 0.5 & 1 \\
Ascorbic acid $(\mathrm{mg})$ & 400 & 400 & 400 & 400 \\
Aspartame $(\mathrm{mg})$ & 5 & 5 & 5 & 5 \\
Mannitol (mg) & 100 & 100 & 100 & 100 \\
Methyl paraben $(\mathrm{mg})$ & 10 & 10 & 10 & 10 \\
Water (ml) & 10 & 10 & 10 & 10 \\
\hline
\end{tabular}


number of times the film could be folded at the same place without breaking gave the value of folding endurance. The procedure was repeated for three times, and average value was calculated.

\section{Tensile strength}

Tensile strength was measured using analog tensile tester (model TKG, FSA, India) in triplicate. Tensile strength computed from the applied load at rupture and cross-sectional area of fractured film from the following equation.

Tensile strength $\left(\mathrm{N} / \mathrm{mm}^{2}\right)=$ breaking force $(\mathrm{N}) /$ cross-sectional area of sample $\left(\mathrm{mm}^{2}\right)$

\section{Percentage elongation}

Percentage elongation was calculated by measuring the increase in length of the film after tensile strength measurement by using the following formulae.

Percentage elongation $=\left[\mathrm{L}-\mathrm{L}_{0}\right] \times 100 / \mathrm{L}_{0}$ Where, $\mathrm{L}$ was the Final length, $\mathrm{L}_{0}$ was initial length. ${ }^{[1]]}$

\section{Time to dissolve the film}

One square centimeter of film of each formula was added to $50 \mathrm{ml}$ of distilled water to determine the time to dissolve the films, and the times were noted. The procedure was repeated, and average value was determined in seconds.

\section{Estimation of drug content}

Film equivalent to $10 \mathrm{mg}$ of drug was weighed accurately and transferred to a glass beaker; to it, $10 \mathrm{ml}$ of methanol was added. The contents were thoroughly mixed, sonicated for $5 \mathrm{~min}$, filtered, and from filtrate, $0.1 \mathrm{ml}$ was taken in $10 \mathrm{ml}$ volumetric flask and made up the volume with distilled water. Then absorbance was measured at $224.2 \mathrm{~nm}$ using UV-visible spectrophotometer. Amount of drug present was calculated using the calibration curve. The procedure was repeated thrice and average drug content $(\% \mathrm{w} / \mathrm{v})$ was calculated.

\section{In vitro drug release studies of zolmitriptan drug loaded films}

In vitro dissolution studies were carried out using USP-II paddle apparatus with $\mathrm{pH} 6.4$ phosphate buffer as the dissolution medium. The dissolution baskets were filled with $200 \mathrm{ml}$ of dissolution medium, and the temperature was maintained at $37 \pm 0.5^{\circ} \mathrm{C}$ throughout the study, and the dissolution was carried for $45 \mathrm{~min}$. Samples were withdrawn at the time intervals of 2, 4, 6, 8, 10, 15, 30, $45 \mathrm{~min}$. Sink conditions were maintained by replacing equal volume of buffer during dissolution to mimic the in vivo conditions. Absorbance was measured for collected samples after making necessary dilutions with buffer using UV-visible spectrophotometer, and amount of drug released was calculated from calibration curve.

\section{Drug interaction studies}

Fourier transform infrared spectroscopy

Preparation of samples to obtain FTIR spectrum

Fourier transformer Infrared spectroscopy (FTIR) spectra were recorded using an FTIR spectrophotometer (Shimadzu). The samples were previously ground and mixed thoroughly with potassium bromide, an infrared matrix, at 1:5 (sample: $\mathrm{KBr}$ ) ratio. The $\mathrm{KBr}$ discs were prepared by compressing the powders at a pressure of 5 tons for $5 \mathrm{~min}$ in a hydraulic press. Forty scans were obtained at a resolution of $4 \mathrm{~cm}^{-1}$, from 4000 to $400 \mathrm{~cm}^{-1}$.

\section{Stability studies}

Films of formulae $\mathrm{X}_{2}$ were wrapped in a butter paper followed by aluminium foil and kept in an aluminium pouch which was heat sealed at the end and Stored at $30^{\circ} \mathrm{C}$ and $60 \%$ relative humidity. The films were evaluated periodically for percent drug content and time to dissolve the film. Stability studies were carried out for a period of 3 months.

\section{RESULTS AND DISCUSSION}

Solubility studies of zolmitriptan in different buffers The salivary $\mathrm{pH}$ is not same for all the individuals; it varies depending on the person's diet, health condition, and other factors. The $\mathrm{pH}$ of the normal individual is in the range of 6.2-7.4. As the oral films are intended to dissolve within the oral cavity in saliva and release the drug, the solubility studies of zolmitriptan were conducted in different buffers within the salivary $\mathrm{pH}$ range and the results are displayed in Table 4. Zolmitriptan is found to be more soluble in phosphate buffer $\mathrm{pH}$ 6.4, and therefore, this buffer was used as the dissolution medium to perform in vitro drug release studies.

\section{Screening of the film formers}

Natural polymers such as pectin, gelatin, and sodium alginate were screened for the preparation of films because these polymers are freely soluble in water, nontoxic and biocompatible, nonirritant, devoid of side effects, and have good wetting and spreadability properties. These polymers also exhibit good tensile strengths, readily available, and economical. ${ }^{[12]}$ The films were casted by solvent casting technique on a plain glass plate and examined for their physical and mechanical properties such as appearance, thickness, folding endurance, and time to dissolve the film. The results were shown in Table 5. Based on these physical and mechanical properties and disintegration time, sodium alginate was found to be the best polymer, and hence, this polymer was used for further study.

\begin{tabular}{llc}
$\begin{array}{l}\text { Table 4: Solubility studies of zolmitriptan in } \\
\text { different buffers }\end{array}$ & \\
\hline S.NO & pH & Solubility $(\mathbf{m g} / \mathrm{ml})$ \\
\hline 1 & 6.4 & $12.2 \pm 0.01$ \\
2 & 6.8 & $4.76 \pm 0.03$ \\
3 & 7.4 & $3.09 \pm 0.04$ \\
\hline
\end{tabular}


Casting of drug loaded film and optimization using $2^{2}$ factorial designs

Using $2^{2}$ factorial designs, four formulations were prepared with sodium alginate using the procedure described in experimental methods. The prepared films were evaluated for mechanical, physicochemical properties, drug loading efficiency, in vitro drug release studies, and drug excipient compatibility studies.

\section{Mechanical properties}

\section{Thickness, tensile strength, percent elongation,} elastic modulus, and folding endurance

Thickness of the films increased as the percent weight of the film forming polymer was increased. Tensile strength and percent elongation of the film are important to resist the mechanical movements that occur during the packing, storage, and shipping of the films. All the films possessed good tensile strength. The films of $X_{2}$ were smoother than films of other formulations. ${ }^{[13-15]}$ The folding endurance was highest for the films $X_{2}$. All the mechanical properties of the films are given in Table 6.

\section{Drug loading efficiency}

The percentage drug loading efficiency of all the formulations was in the range of $68.34 \pm 0.5 \%-94.70 \pm 0.7 \%$. The drug loading efficiency was found to be more with the formula $X_{2}$, and the results were endowed in Table 6 . From the factor analysis, it was observed that polymer had a negative effect on percentage drug content.

\section{In vitro drug release studies}

In vitro drug release studies were carried out for $45 \mathrm{~min}$. The cumulative percent drug released, rate of drug release, and

\begin{tabular}{|c|c|c|c|}
\hline $\begin{array}{l}\text { Name of the polymerl } \\
\text { properties }\end{array}$ & Pectin & $\begin{array}{l}\text { Sodium } \\
\text { alginate }\end{array}$ & Gelatin \\
\hline Film forming capacity & Good & Very good & $\begin{array}{l}\text { Film was } \\
\text { not formed }\end{array}$ \\
\hline Thickness $(\mathrm{mm}) \pm S D^{*}$ & $0.942 \pm 0.14$ & $0.712 \pm 0.12$ & ------ \\
\hline Folding endurance $\pm S D^{*}$ & $26 \pm 5$ & $29 \pm 5$ & -------- \\
\hline Disintegration time $\pm S D^{*}$ & $7 \pm 2 \min$ & $2.5 \pm 1.2 \min$ & ------- \\
\hline Stickiness & Not sticky & Not sticky & ------- \\
\hline
\end{tabular}

$\mathrm{T}_{50}$ were computed using first order rate equation. And it was evident from the $R^{2}$ values that the rate of drug release in all the compositions followed first order kinetics. The dissolution data were also plotted in accordance with the Hixson-Crowell cube root law, i.e., the cube root of the initial concentration minus the cube root of percent remained, as a function of time and a nonlinear relationship was observed in all cases. The drug release profiles did not follow Hixon-crowel model. All the dissolution profiles were shown in Figures 1 and 2.

\section{Factor effect on \% drug release, disintegration time} and percent drug released

The responses considered were $\%$ drug released at $30 \mathrm{~min}$, disintegration time and $\%$ drug content of films. ${ }^{[16,17]}$

\section{Effect of factor-A-polymer concentration}

Factor $A$ effect was calculated by subtracting the average responses of all experimental runs for which A was at its low level from the average responses of all experimental runs for which $A$ was at its high level using the following formula.

Main effect of $\mathrm{A}=\left(\mathrm{a}_{2} \mathrm{~b}_{1}-\mathrm{a}_{1} \mathrm{~b}_{1}\right)+\left(\mathrm{a}_{2} \mathrm{~b}_{2}-\mathrm{a}_{1} \mathrm{~b}_{2}\right)$

\section{Effect of factor-B-plasticizer quantity}

Factor $B$ effect was calculated by subtracting the average responses of all experimental runs for which $B$ was at its low level from the average responses of all experimental runs for which B was at its high level using the following formula. ${ }^{[18,19]}$

Main effect of $B=\left(b_{2} a_{1}-b_{1} a_{1}\right)+\left(b_{2} a_{2}-b_{1} a_{2}\right)$

The factor effects were given in Table 7 . The polymer concentration had negative effect on the percentage of drug release and drug loading efficiency indicating that the rate of drug release and drug loading efficiency decreased as the polymer concentration was increased. The plasticizer had negligible or no effect on the percentage of drug release. The polymer concentration had positive effect on disintegration time indicating that with increasing polymer concentration, disintegration time was increased, whereas plasticizer had negligible influence on disintegration time. Interaction plots

\begin{tabular}{|c|c|c|c|c|c|c|c|}
\hline S.NO & Code & $\begin{array}{l}\text { Thickness } \\
\text { in }(\mathrm{mm})\end{array}$ & $\begin{array}{c}\text { Folding } \\
\text { endurance }\end{array}$ & $\begin{array}{c}\text { Tensile } \\
\text { strength (MPa) }\end{array}$ & $\begin{array}{c}\text { Percent } \\
\text { elongation }\end{array}$ & $\begin{array}{l}\text { Disintegration } \\
\text { time (sec) }\end{array}$ & $\begin{array}{l}\text { Percent Drug loading } \\
\text { efficiency }(w / w)\end{array}$ \\
\hline $\begin{array}{l}1 \\
2 \\
3 \\
4\end{array}$ & $\begin{array}{l}X_{1}(1) \\
X_{2}(b) \\
X_{3}(a) \\
X_{4}^{3}(a b)\end{array}$ & $\begin{array}{l}0.775 \pm 0.20 \\
0.698 \pm 0.13 \\
1.318 \pm 0.22 \\
1.240 \pm 0.11\end{array}$ & $\begin{array}{l}26 \pm 6 \\
29 \pm 4 \\
23 \pm 7 \\
36 \pm 2\end{array}$ & $\begin{array}{l}3.4 \pm 0.4 \\
4.7 \pm 0.5 \\
4.2 \pm 0.8 \\
3.9 \pm 0.3\end{array}$ & $\begin{array}{c}56.8 \pm 1.6 \\
62.13 \pm 1.9 \\
64.32 \pm 3.2 \\
68.41 \pm 2.43\end{array}$ & $\begin{array}{l}175 \pm 3.1 \\
180 \pm 2.5 \\
255 \pm 1.2 \\
280 \pm 1.7\end{array}$ & $\begin{array}{l}90.33 \pm 0.2 \\
94.70 \pm 0.7 \\
76.02 \pm 0.3 \\
68.34 \pm 0.5\end{array}$ \\
\hline
\end{tabular}

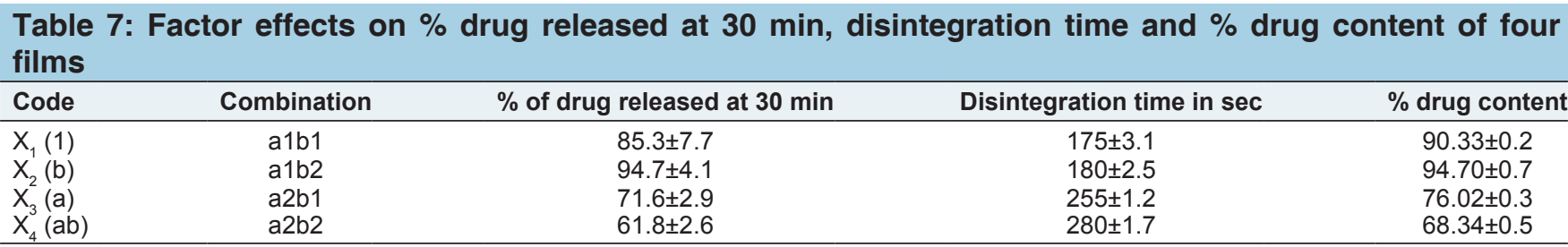


as showed in Figure 3 also revealed that plasticizer at both the levels of polymer did not have any influence on drug loading efficiency, in vitro drug release and disintegration time. But the films were tackier when the plasticizer concentration is at high level because the plasticizer softens the polymer. ${ }^{[20,21]}$

\section{Drug excipient compatibility studies}

Drug excipient compatibility studies were carried out by FTIR, and the results were given in Figure $4 \mathrm{a}$ and $\mathrm{b}$. The FTIR spectra confirmed the absence of drug excipient interaction.

\section{Stability studies}

The films did not show any statistically significant change in appearance, $\%$ drug content, and disintegration time on storage. The $\%$ drug content and disintegration responses were same as that of the responses before the storage. This indicated that $X_{2}$ film was stable after storage.

\section{CONCLUSION}

From the above experimental results, it can be concluded that sodium alginate had good film forming properties and could

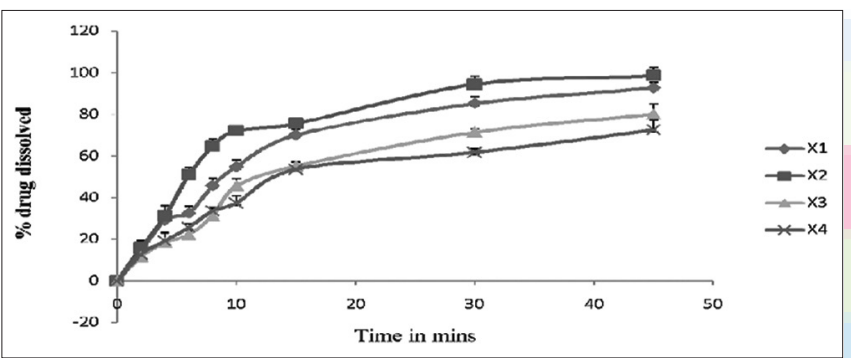

Figure 1: A plot of cumulative percent drug released versus time $(n=3$, mean \pm standard deviation)

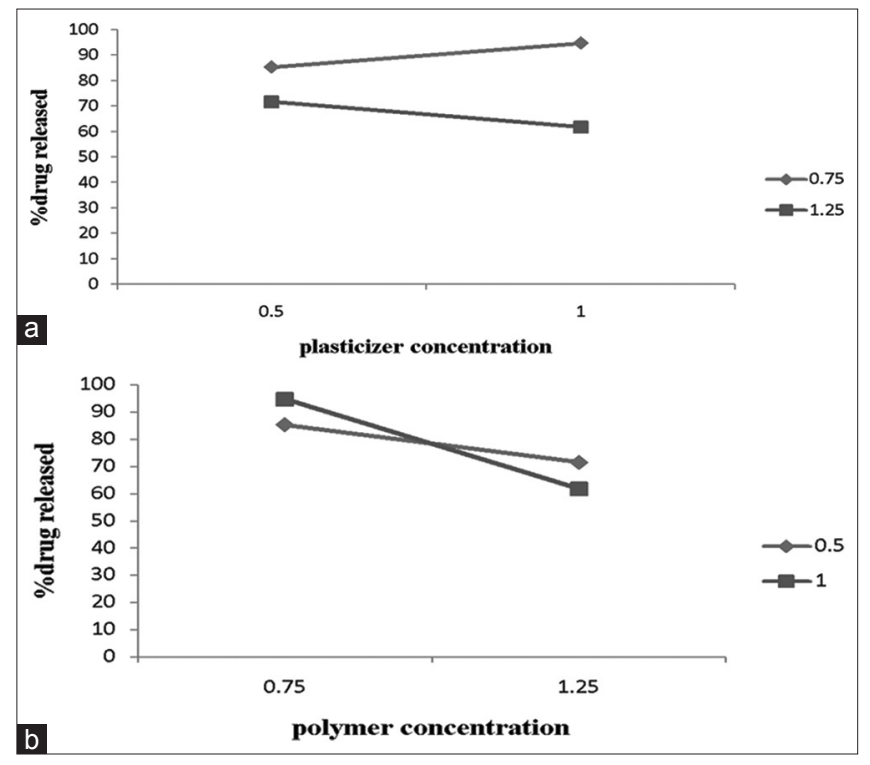

Figure 3: (a) Interaction plot showing the influence of plasticizer concentration on drug release (b) Interaction plot showing the influence of polymer concentration on drug release be used for the preparation of OSF. With increasing polymer concentration, the drug loading efficiency and the rate of drug release were decreased, and this was confirmed from the interaction plots and calculating the factor effects. Plasticizer concentration did not have statistically significant influence on any of these responses at both the levels of polymer conc. Maximum drug loading efficiency was found in $X_{2}$ formulation and the rate of drug release followed first order kinetics.

\section{Financial support and sponsorship}

Nil.

\section{Conflicts of interest}

There are no conflicts of interest.

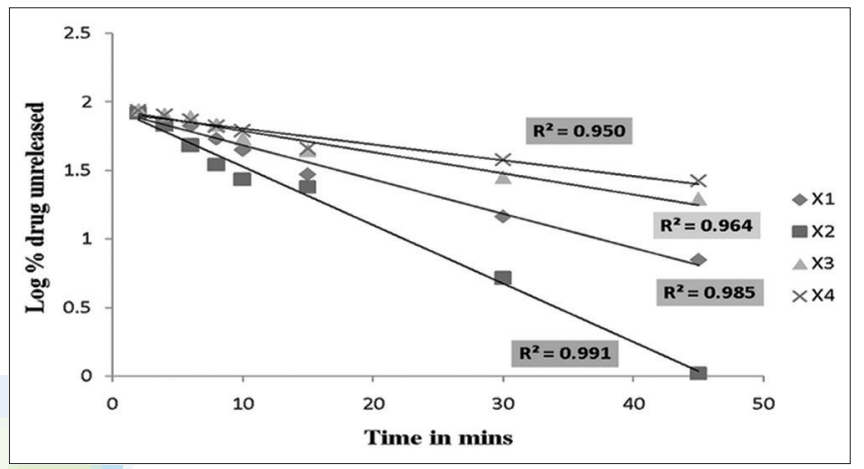

Figure 2: Log percent drug unreleased as a function of time $(n=3$, mean \pm standard deviation)

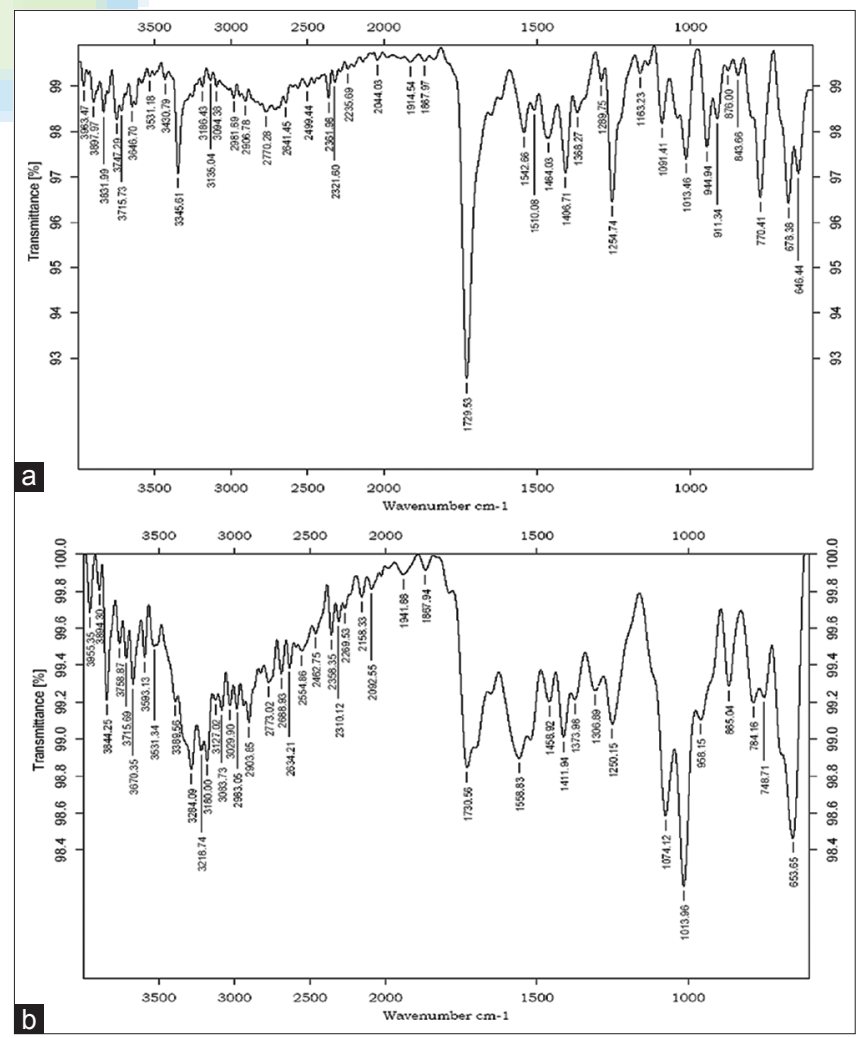

Figure 4: (a) Infrared spectrum of zolmitriptan. (b) Infrared spectrum of $X_{2}$ formulation 


\section{REFERENCES}

1. Migraines and Brain Damage. A practical guide for nutritional and traditional health care. 2008. Available from: http://www. herbs2000.com.

2. Silberstein SD. Migraine symptoms: Results of a survey of self-reported migraineurs. Headache 1995;35:387-96.

3. Becker WL. Migraine-associated symptoms: Clinical significance and management. Can J Clin Pharmacol 1999;6 Suppl A: 15A-9A.

4. Zolmitriptan. Available from: http://www.drugs.com.

5. Dowson AJ, MacGregor EA, Purdy RA, Becker WJ, Green J, Levy SL. Zolmitriptan orally disintegrating tablet is effective in the acute treatment of migraine. Cephalalgia 2002;22:101-6.

6. Zolmitriptan spray - nasal, Zomig. Available from: http://www. Medicine net.com.

7. David BT, Paul B. Pharmaceutical manufacturing, Remington: The Science and Practice of Pharmacy. Vol. 1. Philadelphia: Lippincott Williams and Wilkins; 2006. p. 828.

8. Lewis DW, Winner P, Hershey AD, Wasiewski WW; Adolescent Migraine Steering Committee. Efficacy of zolmitriptan nasal spray in adolescent migraine. Pediatrics 2007;120:390-6.

9. Dixit RP, Puthli SP. Oral strip technology: Overview and future potential. J Control Release 2009;139:94-107.

10. Kaur M, Rana AC, Setha N. Fast dissolving films: An innovative drug delivery system. Int J Pharm Res Allied Sci 2013;2:14-24.

11. Anthony NA, Kenneth CJ. Pharmaceutical Experimental Designs. CRC press: Taylor and Francis; 2006. p. 131-4.

12. Nidhi PS, Vaishali AK, Anwar SD, Minal NB. Development of fast dissolving oral thin films of ambroxol hydrochloride: Effect of formulation variables. J Adv Pharm Res 2011;2:102-9.

13. Liew KB, Tan YT, Peh KK. Characterization of oral disintegrating film containing donepezil for Alzheimer disease. AAPS PharmSciTech 2012;13:134-42.

14. Kulakarni VS, Butte Kishore D, Rathod Sudha S. Natural polymers - A comprehensive review. J Res Pharm Biomed Sci 2012;3:1597-613.

15. Dinge A, Nagarsenker M. Formulation and evaluation of fast dissolving films for delivery of triclosan to the oral cavity. AAPS PharmSciTech 2008;9:349-56.

16. El-Setouhy DA, Abd El-Malak NS. Formulation of a novel tianeptine sodium orodispersible film. AAPS PharmSciTech 2010;11:1018-25

17. Mohamed MI, Haider M, Mohamed AM. Buccal mucoadhesive films containing antihypertensive drug: In vitrolin vivo evaluation. J Chem Pharm Res 2011;3:665-21.

18. Perez JA, Gonz alez A, Oliva JM, Balleteros I, Manzanares P. Effect of process variables on liquid hot water pretreatment of wheat straw for bioconversion to fuel-ethanol in a batch reactor. J Chem Technol Biotechnol 2007;82:929-38.

19. Daniel WW. Biostatistics: A Foundation for Analysis in the Health Sciences. $7^{\text {th }}$ ed. Wiley: John Willy and Sons; 1998. p. 341-3.

20. Box GEP, Hunter WG, Hunter JS. Statistics for Engineers: An Introduction to Design, Data Analysis, and Model Building. New York: John Wiley and Sons; 1978.

21. Wesseling M, Kuppler F, Bodmeier R. Tackiness of acrylic and cellulosic polymer films used in the coating of solid dosage forms. Eur J Pharm Biopharm 1999;47:73-8. 